\title{
Guided Scrambling As a Peak to Average Power Ratio Reduction Technique for Digital Video Broadcasting-Terrestrial 2
}

(Date received: 20.05.17/Date accepted: 06.02.18)

\author{
Ir. V. Jeewa \\ Lee Kong Chian Faculty of Engineering \& Sciences, \\ Department of Electrical \& Electronic Engineering, \\ University Tunku Abdul Rahman, \\ Kajang, Malaysia \\ Email: jeewa@utar.edu.my
}

\section{ABSTRACT}

Analogue Broadcast Transmitters are being replaced by Digital Transmitters based on standards using Orthogonal Frequency Division Multiplex (OFDM). However, high Peak to Average Power Ratio (PAPR) is limiting the performance of digital transmitters and several techniques have been proposed to mitigate it including amplitude clipping, coding, multiple signal representation techniques, selected mapping or partial transmit sequences. As a general rule, these techniques achieve PAPR reduction at the expense of an increase in transmitted signal power, an increase in BER, a higher loss in data rate, or an increase in computational complexity. Therefore, an alternative technique using Guided Scrambling is presented here.

Keywords: DVB-T2, Guided Scrambling, OFDM, PAPR.

\subsection{INTRODUCTION}

Orthogonal Frequency Division Multiplex (OFDM) is a sum of $n$ modulated subcarriers with different frequencies. The envelope of the sum varies and at times the components add up to high peaks, putting stress on the high power amplifier of the digital transmitter. The theoretical maximum PAPR for an OFDM system modulated with Multi Phase Shift Keying (MPSK) where all the amplitudes are the same resulting in a constant envelope modulated signal is:

$$
\text { Maximum } P A P R=N
$$

where

\section{N=Number of sub-carriers}

In the case of M-Quadrature Amplitude Modulation (M-QAM) where there is variation in envelope, the formula is:

$$
\text { Maximum } P A P R=\frac{3 N(\sqrt{M}-1)}{\sqrt{M}+1}
$$

where

$$
\begin{aligned}
& M=\text { QAM Modulation order } \\
& N=\text { Number of sub-carriers }
\end{aligned}
$$

Comparing (1) and (2), it can be deduced that the PAPR for M-QAM increases by the factor $3(\sqrt{ } \mathrm{M}-1) /(\sqrt{ } \mathrm{M}+1)$ leading to the observation that any increase in number of subcarriers or change in constellation mode from QPSK to 64 QAM would contribute to increasing the maximum PAPR.

A theoretical PAPR value of $40 \mathrm{~dB}$ can be obtained but which has a disastrous effect on transmitters. Usually a practical limit of $12-15 \mathrm{~dB}$ is imposed on the operation of the Digital TV transmitter [1]. The demand for higher data rates to cater for High Definition TV (HDTV) and future Ultra HDTV transmission has pushed up the number of subcarriers from $8 \mathrm{~K}$ to $32 \mathrm{~K}$ and higher order of uniform constellation mode from 64 QAM to 256 QAM. It should be noted that the second generation Digital Terrestrial TV standard from the USA namely Advanced Television Systems Committee ATSC 3.0 has been designed to utilise non uniform constellation from 16 QAM to 4096 QAM.

In order to avoid this problem, the power amplifier must have a large back off and operate at lower average power level resulting in an inefficient transmitter. Thus Peak Average Power Ratio (PAPR) reduction needed to be employed and several schemes have been proposed. These techniques can be classified into three main categories: signal distortion techniques, multiple signaling and probabilistic techniques and coding techniques. This research is based on multiple signalling techniques using Guided Scrambling and applied to the second generation digital terrestrial broadcast system namely the Digital Video Broadcast Terrestrial-2 (DVB-T2) which was standardised in 2008.

As a matter of fact, the DVB-T2 system can be configured to have $1 \mathrm{~K}, 2 \mathrm{~K}, 4 \mathrm{~K}, 8 \mathrm{~K}, 16 \mathrm{~K}$ or $32 \mathrm{~K}$ subcarriers and uniform QAM constellation modes of 4 QAM (QPSK), 16 QAM, 64 QAM and 256 QAM. This is a significant advancement in technology when compared to the first generation DVB-T which was using only $8 \mathrm{~K}$ sub-carriers and the highest constellation mode of 64 QAM.

\subsection{LITERATURE REVIEW}

Many techniques have been proposed including amplitude clipping; coding; selected mapping or partial transmit sequences [2]. The simplest technique for PAPR reduction is amplitude clipping which limits the peak envelope of the input signal to a predetermined value. However the distortion caused by 


\section{GUIDED SCRAMBLING AS A PEAK TO AVERAGE POWER RATIO REDUCTION TECHNIQUE FOR DIGITAL VIDEO BROADCASTING - TERRESRIAL 2}

amplitude clipping causes noise which falls both in-band and out of band. In-band distortion cannot be reduced by filtering and results in error performance degradation, while out-of-band radiation reduces spectral efficiency.

Coding can also be used to reduce the PAPR by specific selection of those code words that minimize or reduce it .However, this approach suffers from the need to perform an exhaustive search to find the best codes and to store large look up tables for encoding and decoding, especially for a large number of subcarriers.

In the Partial Transmit Sequence technique, an input data block of $\mathrm{N}$ symbols is partitioned into disjoint sub-blocks. The sub-carriers in each sub-block are weighted by a phase factor for that sub-block. The selection of the phase factors is limited to a set with a finite number of elements to reduce the search complexity. However, the search complexity increases exponentially with the number of sub-blocks and side information has to be transmitted to the receiver.

In the Selected Level Mapping technique, the transmitter generates a set of different candidate data blocks, all representing the same information as the original data block, and selects the most favorable for transmission. Each data block has to be multiplied by different phase sequences and again information about the selected phase sequence should be transmitted to the receiver as side information resulting in more bit rate peculiarities.

Hence, further research in this area was carried out by studying Guided Scrambling which was introduced as line coding technique for high bit rate fiber optic transmission systems [3]. A previous research paper elaborated on the use of Guided Scrambling to reduce PAPR in OFDM but the technique was limited to $N=256$ subcarriers, QPSK modulation mode and an unstated number of information bits [4]. Another paper on the subject utilised an OFDM system of $N=256$ subcarriers, BPSK modulation and again an unstated number of information bits [5]. There is a need to state the length of source word or information bits as it may affect the scrambling process and overall design.

\subsection{GUIDED SCRAMBLING}

A bit stream may contain a bit pattern sequence that can cause correlation of the sub-carriers leading to a buildup of the peak value and increase the amplitude of the signal. Scrambling randomises a bit pattern but does not ensure a balanced line transmission. Guided Scrambling is a line coding technique which offers balanced, highly efficient transmission with a high transition density [6] [7].

The proposed technique would augment and scramble the information data in order to improve the performance of OFDM especially for a high number of sub-carriers and constellation modes which in the case of DVB-T2 can reach up to 32,000 subcarriers and also 256 QAM constellation mode. As explained in section 2, past research into PAPR reduction was mostly confined to smaller number of sub-carriers and BPSK constellation. From a review of previous technical papers on this topic, it can be deduced that there is a research gap in this particular area. Although Guided Scrambling has been described as a technique for PAPR minimisation, none of the related papers have included a DVB-T2 or equivalent model in any part of the design stages.
Another important factor that must be taken into account is that the information bit word length or Data Field is rather lengthy with a maximum capacity of 53760 bits. The long Data Field may be a constraint and any scrambling method must be capable of handling it. In addition to this, DVB-T2 operates at very high data rate with a maximum value of $45 \mathrm{Mb} / \mathrm{s}$. The new technique is also designed to take into consideration that the scrambled data must pass through many stages of signal processing conducted by the DVB-T2 model.

A single technique may not be able to minimise PAPR significantly and thus most design implement two different techniques that act in tandem or better described as a dual stage. The complete design, uses Guided Scrambling technique as a first stage to lower the PAPR to a value that can be set as the clipping level for the threshold, to be operated upon by the second stage utilising Tone Reservation Carriers. Optimisation of location and the number of subcarriers need to be undertaken.

The combined design should yield a better performance than a single approach. However this paper can only provide details of the first stage as research on the dual stage is still ongoing and yet to be completed. It is also to be noted that the present work described is confined only to the DVB-T2 transmitter chain and not the receiver end. The main reason is that PAPR is measured at the transmitter output and not the receiver.

\subsection{The Mathematical Concept}

A bit stream can be represented by the polynomial:

$$
s(x)=c_{j-1} x^{j-1}+c_{j-2} x^{j-2}+c_{j-3} x^{j-3} \ldots \ldots c_{1} x+c_{0}
$$

with the following terms defined :

$d(x)=$ scrambling polynomial, of degree $\mathrm{d}$.

$s(x)=$ source bit stream.

$a(x)=$ augmented source word

$q(x)=$ quotient resulting from the division of $\mathrm{a}(\mathrm{x})$ by $\mathrm{d}(\mathrm{x})$.

Examination of scrambling division reveals the property that the value of the most significant bit can affect the values of many quotient bits. For example if:

$s(x)=01001010001001010100101$

$d(x)=100101$

the transmitted quotient would be:

\section{$q(x)=01000000001000000100000$}

This unbalanced sequence has few transitions does not only satisfy line code criteria but would cause many of the subcarriers to group together resulting in peaks.

However, if the first bit of $s(x)$ had been a One instead of a Zero, then: 


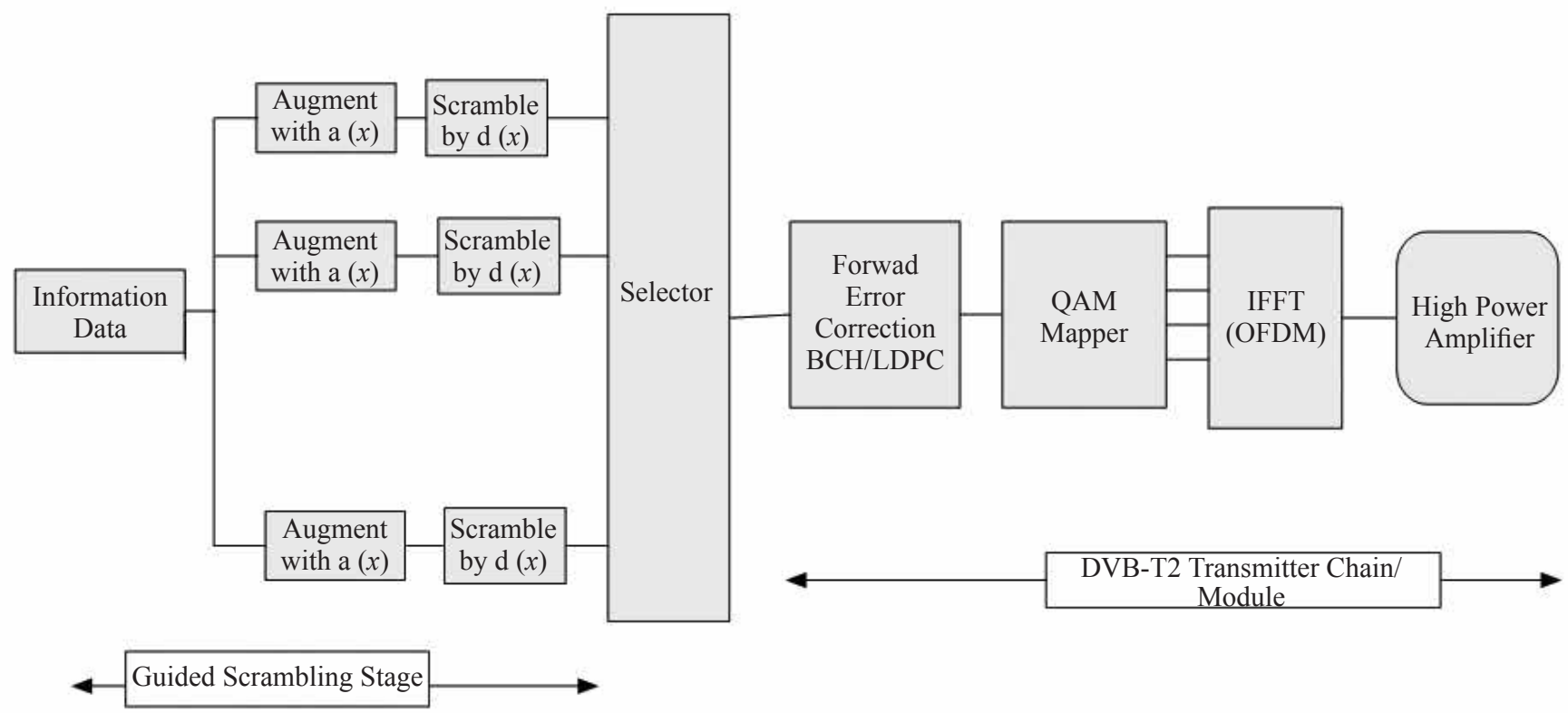

Figure 1: PAPR Reduction Techniques: Guided Scrambling

$s(x)=11001010001001010100101$

and division by the same $\mathrm{d}(\mathrm{x})$ results in the quotient

$$
q(x)=11010110010111000010111
$$

This sequence is suitable as it is balanced with more transition [8]. From analysis and computer simulation, it has been determined that appropriate augmentation of the information bit stream will guide the scrambling process to produce a balanced quotient bit stream with a high transition density. The extra bits should be augmented onto the most significant bit of the bit stream as it is the first few bits that effect most the pattern and hence the transition density.

\subsection{The Configuration}

Figure 1 shows the conceptual model consisting of a Guided Scrambling stage and a simplified DVB-T2 transmitter stage. The function of the Guided Scrambling stage is to append the extra bits to the information bit stream. The DVB-T2 stage is a modification of the Matlab DVB-T2 Common Simulation Platform (DVB-T2 CSP) from the British Broadcasting Corporation (BBC) [9]. The DVB-T2 CSP complies with all technical specifications set by the international standard namely ETSI EN 302755 V1.3.1 (2012-04) [10]. It comprises of an end to end digital broadcast chain including the transmitter, channel and receiver. The complete DVB-T2 system architecture is rather complex as it encompasses a wide range of advanced technologies such as Multiple Physical Layer Pipes, Signalling and a variety of Interleavers based on time, bit, cell and frequency. Some of these technologies are not necessary to be included at the present state of research, but may be incorporated at the final state to validate the research.

Thus a simplified Matlab programme was designed with the Guided Scrambling input stage and basic digital transmitter components with only a single Physical Layer Pipe. The DVB-T2 transmitter stage consists of the Bose Chaudhuri Hocquenghem $(\mathrm{BCH})$ Outer Coder, Low Density Parity Check (LDPC) Inner Coder, Quadrature Amplitude Modulation (QAM) Mapper and the Inverse Fast Fourier Transform (IFFT) modules.

The information bit stream was augmented with 1-4 bits and passed into the Forward Error Correction subsystem comprising the concatenated BCH/LDPC coders. The bit stream was mapped onto a QAM modulator and processed by the IFFT modules that generate the OFDM signal. The PAPR of the varying bit streams caused by augmented bits was calculated from the ratio between maximum power and average power as indicated by this formula:

PAPR $=10 . \log \left\{\frac{\max |x(t)|^{2}}{\text { mean }\left[|x(t)|^{2}\right]}\right\}$

The theoretical Maximum PAPR for an OFDM system with $\mathrm{N}$ non modulated sub-carriers is based on the formula:

\section{Max PAPR nonmodulated $=N$}

Equation (5) indicates that a DVB-T2 system with a 32,000 non modulated subcarriers, would in theory reach a maximum PAPR of $45 \mathrm{~dB}$ which is indeed excessive for the High Power Amplifier [11]. 


\subsection{Simplified Matlab Code/Pseudo Code}

A very simplified Matlab code is shown here to lend more clarity to the methodology used.

\author{
1. $c l c$ \\ 2. clear all \\ 3. data $=$ randint \\ 4. dataBinaryl=reshape $(\operatorname{de} 2 b i($ data, 8, 'left-ms $b$ ').', 1, []) \\ 5. dataBinary $2=$ reshape $($ dataBinary $1,250,[7)$; \\ 6. $B=7$ \\ 7. $B=\operatorname{de} 2 b i(B, 3)$ \\ 8. $g s l=B$; \\ 9. $g s 2=$ [gs1 dataBinary 2$]$;
}

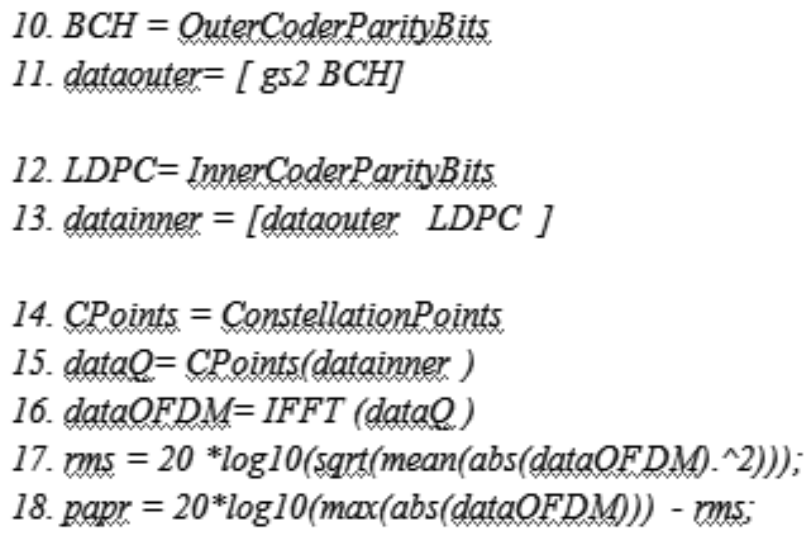

\author{
$\%$ generate random numbers for \\ data \\ $\%$ convert random integers to \\ binary \\ $\%$ one packet per column \\ $\%$ initiate fixed integer for \\ augmented bits \\ $\%$ convert random integers to 3 \\ binary bits \\ $\%$ Guided Scrambling bits-3 \\ $\%$ append augmented bits to data \\ packet \\ $\%$ BCH Encoder \\ $\%$ Append $B C H$ parity bits - \\ Outer Coder \\ $\%$ LDPC Encoder \\ $\%$ Append LDPC parity bits - \\ Inner Coder \\ $\% \quad Q A M$ Points \\ $\%$ QAM Mapper \\ $\%$ OFDM subcarriers \\ \% Calculate Peak to Average
Power Ratio
}

\section{RESULTS \& PERFORMANCE}

The Matlab programme was configured to have the technical parameters specified here:

(i) Information Data input: 41220 bits ( Max Data Field in

(ii) Outer Encoder DVBT-2 $=53760$ bits $)$

(iii) Inner Encoder

BCH $(54000,53840)$

(iv) Code Rate

: LDPC $(64000,54000)$

(v) Augmented Bits $: 5 / 6$

(vi) No. of Subcarriers

: $1,2,3$ or 4 Bits

: $32 \mathrm{~K}$ or $8 \mathrm{~K}$

(vii) Constellation Order : 64 QAM or 256 QAM

Performance of the different configurations, were recorded separately into the following category of tables laid out here;

\section{(a) CATEGORY A:}

Tables 1 till 4 show results associated with technical parameters specified with 1, 2, 3 or 4 Augmented Bits; 256 QAM and 32,000 subcarriers.

\section{(b) CATEGORY B:}

Tables 5 till 8 show results associated with technical parameters specified with 1, 2, 3 or 4 Augmented Bits; 64 QAM and 32,000 subcarriers.

\section{(c) CATEGORY C:}

Tables 9 till 12 show results associated with technical parameters specified with 1, 2, 3 or 4 Augmented Bits; 256 QAM and 8,000 subcarriers.

\section{(d) CATEGORY D:}

Tables 9 till 15 show results associated with technical parameters specified with 4 Augmented Bits; 256 QAM and 32,000 subcarriers. However, the initial randomised bit sequence was not used but instead information bits have been deliberately set to all ONES, all ZEROES or Balanced ONES \& ZEROES.

As a precaution and to ensure that the design was working, the programme was set to calculate the PAPR without the use of any reduction technique. Without any augmented bits, the PAPR performance for Category A was $12.27 \mathrm{~dB}$, Category B was $11.84 \mathrm{~dB}$ and Category $\mathrm{C}$ was $10.5 \mathrm{~dB}$.

Table 1: Category A - PAPR for Technical Parameters; 4 Augmented Bits, 256 QAM \& 32,000 subcarriers

\begin{tabular}{|c|c|c|c|c|}
\hline $\begin{array}{c}\text { Constellation } \\
\text { Mode }\end{array}$ & $\begin{array}{l}\text { No. of } \\
\text { Scrambling } \\
\text { Bits }\end{array}$ & $\begin{array}{l}\text { Scrambling } \\
\text { Sequence }\end{array}$ & PAPR & Comment \\
\hline \multirow[t]{9}{*}{256 QAM } & 4 & 0000 & 15.53 & Max PAPR \\
\hline & & 0000 & 15.53 & Max PAPR \\
\hline & & 0001 & 13.87 & \\
\hline & & 0010 & 13.91 & \\
\hline & & 0011 & 13.55 & \\
\hline & & 0100 & 13.91 & \\
\hline & & 0101 & 13.50 & Min.PAPR \\
\hline & & 0110 & 13.58 & \\
\hline & & 0111 & 13.63 & \\
\hline
\end{tabular}


Table 1: Category A - PAPR for Technical Parameters ; 4 Augmented Bits, 256 QAM \& 32,000 subcarriers

\begin{tabular}{|c|c|c|c|c|}
\hline $\begin{array}{c}\text { Constellation } \\
\text { Mode }\end{array}$ & $\begin{array}{c}\text { No. of } \\
\text { Scrambling } \\
\text { Bits }\end{array}$ & $\begin{array}{l}\text { Scrambling } \\
\text { Sequence }\end{array}$ & PAPR & Comment \\
\hline & & 1000 & 13.93 & \\
\hline & & 1001 & 13.54 & \\
\hline & & 1010 & 13.50 & Min PAPR \\
\hline & & 1011 & 13.55 & \\
\hline & & 1100 & 13.57 & \\
\hline & & 1101 & 13.62 & \\
\hline & & 1110 & 13.59 & \\
\hline & & 1111 & 13.64 & \\
\hline
\end{tabular}

Note: Without reduction technique PAPR $=12.27$

Table 2: Category A - PAPR for Technical Parameters; 3 Augmented Bits, 256 QAM \& 32,000 subcarriers

\begin{tabular}{|c|c|c|c|c|}
\hline $\begin{array}{c}\text { Constellation } \\
\text { Mode }\end{array}$ & $\begin{array}{c}\text { No. of } \\
\text { Scrambling } \\
\text { Bits }\end{array}$ & $\begin{array}{l}\text { Scrambling } \\
\text { Sequence }\end{array}$ & PAPR & Comment \\
\hline \multirow[t]{8}{*}{256 QAM } & 3 & 000 & 12.26 & Min PAPR \\
\hline & & 001 & 12.28 & \\
\hline & & 010 & 12.38 & \\
\hline & & 011 & 12.34 & \\
\hline & & 100 & 12.31 & \\
\hline & & 101 & 12.33 & \\
\hline & & 110 & 12.40 & Max PAPR \\
\hline & & 111 & 12.36 & \\
\hline
\end{tabular}

Note: Without reduction technique PAPR $=12.27$

Table 3: Category A - PAPR for Technical Parameters; 2 Augmented Bits, 256 QAM \& 32,000 subcarriers

\begin{tabular}{|c|c|c|c|c|}
$\begin{array}{c}\text { Constellation } \\
\text { Mode }\end{array}$ & $\begin{array}{c}\text { No. of } \\
\text { Scrambling } \\
\text { Bits }\end{array}$ & $\begin{array}{c}\text { Scrambling } \\
\text { Sequence }\end{array}$ & \multicolumn{1}{c|}{ PAPR } & Comment \\
\hline 256 QAM & 2 & 00 & 12.09 & Max PAPR \\
\hline & & 01 & 12.05 & \\
\hline & & 10 & 11.98 & \\
\hline & & 11 & 11.94 & Min PAPR \\
\hline
\end{tabular}

Note: Without reduction technique PAPR $=12.27$

Table 4: Category A - PAPR for Technical Parameters; 1 Augmented Bits, 256 QAM \& 32,000 subcarriers

\begin{tabular}{|c|c|c|c|c|}
$\begin{array}{c}\text { Constellation } \\
\text { Mode }\end{array}$ & $\begin{array}{c}\text { No. of } \\
\text { Scrambling } \\
\text { Bits }\end{array}$ & $\begin{array}{c}\text { Scrambling } \\
\text { Sequence }\end{array}$ & PAPR & Comment \\
\hline 256 QAM & 1 & 0 & 12.93 & Min PAPR \\
\hline & & 1 & 13.00 & Max PAPR \\
\hline
\end{tabular}

Note: Without reduction technique $P A P R=12.27$
Table 5: Category B - PAPR for Technical Parameters; 4 Augmented Bits, 64 QAM \& 32,000 subcarriers

\begin{tabular}{|c|c|c|c|c|}
\hline $\begin{array}{c}\text { Constellation } \\
\text { Mode }\end{array}$ & $\begin{array}{c}\text { No. of } \\
\text { Scrambling } \\
\text { Bits }\end{array}$ & $\begin{array}{l}\text { Scrambling } \\
\text { Sequence }\end{array}$ & PAPR & Comment \\
\hline \multirow[t]{16}{*}{64 QAM } & 4 & 0000 & 14.97 & Max PAPR \\
\hline & & 0001 & 13.19 & \\
\hline & & 0010 & 12.90 & \\
\hline & & 0011 & 11.99 & \\
\hline & & 0100 & 12.89 & \\
\hline & & 0101 & 12.78 & \\
\hline & & 0110 & 12.52 & \\
\hline & & 0111 & 11.97 & Min PAPR \\
\hline & & 1000 & 12.99 & \\
\hline & & 1001 & 12.81 & \\
\hline & & 1010 & 12.04 & \\
\hline & & 1011 & 12.04 & \\
\hline & & 1100 & 12.16 & \\
\hline & & 1101 & 12.01 & \\
\hline & & 1110 & 12.05 & \\
\hline & & 1111 & 12.05 & \\
\hline
\end{tabular}

Note: Without reduction technique PAPR $=11.84 \mathrm{~dB}$

Table 6: Category B - PAPR for Technical Parameters; 3 Augmented Bits, 64 QAM \& 32,000 subcarriers

\begin{tabular}{|c|c|c|c|c|}
\hline $\begin{array}{c}\text { Constellation } \\
\text { Mode }\end{array}$ & $\begin{array}{c}\text { No. of } \\
\text { Scrambling } \\
\text { Bits }\end{array}$ & \multicolumn{2}{c|}{$\begin{array}{c}\text { Scrambling } \\
\text { Sequence }\end{array}$} & \multicolumn{2}{c|}{ PAPR } & Comment \\
\hline 64 QAM & 3 & 000 & 14.12 & Max PAPR \\
\hline & & 001 & 11.69 & \\
\hline & & 010 & 11.96 & \\
\hline & & 011 & 11.66 & Min PAPR \\
\hline & & 100 & 12.27 & \\
\hline & & 101 & 13.40 & \\
\hline & & 110 & 11.83 & \\
\hline & & 111 & 11.80 & \\
\hline
\end{tabular}

Note: Without reduction technique PAPR $=11.84 \mathrm{~dB}$

Table 7: Category B - PAPR for Technical Parameters; 2 Augmented Bits, 64 QAM \& 32,000 subcarriers

\begin{tabular}{|c|c|c|c|c|}
$\begin{array}{c}\text { Constellation } \\
\text { Mode }\end{array}$ & $\begin{array}{c}\text { No. of } \\
\text { Scrambling } \\
\text { Bits }\end{array}$ & $\begin{array}{c}\text { Scrambling } \\
\text { Sequence }\end{array}$ & PAPR & Comment \\
\hline 64 QAM & 2 & 00 & 13.55 & \\
\hline & & 01 & 13.62 & Max PAPR \\
\hline & & 10 & 13.53 & Min PAPR \\
\hline & & 11 & 13.57 & \\
\hline
\end{tabular}

Note: Without reduction technique $P A P R=11.84 \mathrm{~dB}$

Table 8: Category B - PAPR for Technical Parameters; 1 Augmented Bit, 256 QAM \& 32,000 subcarriers

\begin{tabular}{c|c|c|c|c|}
$\begin{array}{c}\text { Constellation } \\
\text { Mode }\end{array}$ & $\begin{array}{c}\text { No. of } \\
\text { Scrambling } \\
\text { Bits }\end{array}$ & $\begin{array}{c}\text { Scrambling } \\
\text { Sequence }\end{array}$ & PAPR & Comment \\
\hline 64 QAM & 1 & 0 & 11.49 & Min PAPR \\
\hline & & 1 & 11.61 & Max PAPR \\
\hline
\end{tabular}

Note: Without reduction technique PAPR $=11.84 \mathrm{~dB}$ 


\section{GUIDED SCRAMBLING AS A PEAK TO AVERAGE POWER RATIO REDUCTION TECHNIQUE FOR DIGITAL VIDEO BROADCASTING - TERRESRIAL 2}

Table 9: Category C - PAPR for Technical Parameters; 4 Augmented Bits, 256 QAM \& 8,000 subcarriers

\begin{tabular}{|c|c|c|c|c|}
\hline $\begin{array}{c}\text { Constellation } \\
\text { Mode }\end{array}$ & $\begin{array}{c}\text { No. of } \\
\text { Scrambling } \\
\text { Bits }\end{array}$ & $\begin{array}{l}\text { Scrambling } \\
\text { Sequence }\end{array}$ & PAPR & Comment \\
\hline \multirow[t]{16}{*}{256 QAM } & 4 & 0000 & 12.99 & Max PAPR \\
\hline & & 0001 & 11.28 & \\
\hline & & 0010 & 11.32 & \\
\hline & & 0011 & 10.23 & Min PAPR \\
\hline & & 0100 & 11.33 & \\
\hline & & 0101 & 10.28 & \\
\hline & & 0110 & 10.55 & \\
\hline & & 0111 & 10.32 & \\
\hline & & 1000 & 11.30 & \\
\hline & & 1001 & 10.88 & \\
\hline & & 1010 & 11.09 & \\
\hline & & 1011 & 10.52 & \\
\hline & & 1100 & 11.90 & \\
\hline & & 1101 & 11.23 & \\
\hline & & 1110 & 10.45 & \\
\hline & & 1111 & 10.40 & \\
\hline
\end{tabular}

Note: Without reduction technique PAPR $=10.5 \mathrm{Db}$

Table 10: Category C - PAPR for Technical Parameters; 3 Augmented Bits, 256 QAM \& 8,000 subcarriers

\begin{tabular}{|c|c|c|c|c|}
\hline $\begin{array}{c}\text { Constellation } \\
\text { Mode }\end{array}$ & $\begin{array}{c}\text { No. of } \\
\text { Scrambling } \\
\text { Bits }\end{array}$ & $\begin{array}{l}\text { Scrambling } \\
\text { Sequence }\end{array}$ & PAPR & Comment \\
\hline \multirow[t]{8}{*}{256 QAM } & 3 & 000 & 10.11 & Max PAPR \\
\hline & & 001 & 9.58 & Min PAPR \\
\hline & & 010 & 9.70 & \\
\hline & & 011 & 9.67 & \\
\hline & & 100 & 9.67 & \\
\hline & & 101 & 9.67 & \\
\hline & & 110 & 9.76 & \\
\hline & & 111 & 9.77 & \\
\hline
\end{tabular}

Note: Without reduction technique PAPR $=10.5 \mathrm{~dB}$

Table 11: Category C-PAPR for Technical Parameters; 2 Augmented Bits, 256 QAM \& 8,000 subcarriers

\begin{tabular}{|c|c|c|c|c|}
\hline $\begin{array}{l}\text { Constellation } \\
\text { Mode }\end{array}$ & $\begin{array}{c}\text { No. of } \\
\text { Scrambling } \\
\text { Bits }\end{array}$ & $\begin{array}{l}\text { Scrambling } \\
\text { Sequence }\end{array}$ & PAPR & Comment \\
\hline \multirow[t]{4}{*}{256 QAM } & 2 & 00 & 10.10 & Max PAPR \\
\hline & & 01 & 9.54 & Min PAPR \\
\hline & & 10 & 9.91 & \\
\hline & & 11 & 9.51 & \\
\hline
\end{tabular}

Note: Without reduction technique PAPR $=10.5 \mathrm{~dB}$
Table 12: Category C-PAPR for Technical Parameters; 1 Augmented Bits, 256 QAM \& 8,000 subcarriers

\begin{tabular}{|c|c|c|c|c|}
$\begin{array}{c}\text { Constellation } \\
\text { Mode }\end{array}$ & $\begin{array}{c}\text { No. of } \\
\text { Scrambling } \\
\text { Bits }\end{array}$ & $\begin{array}{c}\text { Scrambling } \\
\text { Sequence }\end{array}$ & PAPR & Comment \\
\hline 256 QAM & 1 & 0 & 10.66 & Max PAPR \\
\hline & & 1 & 9.79 & Min PAPR \\
\hline
\end{tabular}

Note: Without reduction technique PAPR $=10.5 \mathrm{~dB}$

Table 13: Category D - PAPR for Technical Parameters; 4 Augmented Bits, 256 QAM \& 32,000 subcarriers All ONES Sequence for 41220 bits

\begin{tabular}{|c|c|c|c|c|}
\hline $\begin{array}{l}\text { Constellation } \\
\text { Mode }\end{array}$ & $\begin{array}{c}\text { No. of } \\
\text { Scrambling } \\
\text { Bits }\end{array}$ & $\begin{array}{l}\text { Scrambling } \\
\text { Sequence }\end{array}$ & PAPR & Comment \\
\hline \multirow[t]{16}{*}{256 QAM } & 4 & 0000 & 41.04 & Min PAPR \\
\hline & & 0001 & 41.30 & \\
\hline & & 0010 & 41.30 & \\
\hline & & 0011 & 41.56 & \\
\hline & & 0100 & 41.30 & \\
\hline & & 0101 & 41.57 & \\
\hline & & 0110 & 41.56 & \\
\hline & & 0111 & 41.82 & \\
\hline & & 1000 & 41.30 & \\
\hline & & 1001 & 41.57 & \\
\hline & & 1010 & 41.57 & \\
\hline & & 1011 & 41.83 & \\
\hline & & 1100 & 41.56 & \\
\hline & & 1101 & 41.83 & \\
\hline & & 1110 & 41.83 & Max PAPR \\
\hline & & 1111 & 42.10 & \\
\hline
\end{tabular}

Table 14: Category D - PAPR for Technical Parameters; 4 Augmented Bits, 256 QAM \& 32,000 subcarriers All ZEROES Sequence for 41220 bits

\begin{tabular}{|c|c|c|c|c|}
\hline $\begin{array}{c}\text { Constellation } \\
\text { Mode }\end{array}$ & $\begin{array}{c}\text { No. of } \\
\text { Scrambling } \\
\text { Bits }\end{array}$ & $\begin{array}{l}\text { Scrambling } \\
\text { Sequence }\end{array}$ & PAPR & Comment \\
\hline \multirow[t]{16}{*}{256 QAM } & 4 & 0000 & 42.10 & Max PAPR \\
\hline & & 0001 & 42.06 & \\
\hline & & 0010 & 42.07 & \\
\hline & & 0011 & 42.03 & \\
\hline & & 0100 & 42.03 & \\
\hline & & 0101 & 42.03 & \\
\hline & & 0110 & 42.04 & \\
\hline & & 0111 & 42.00 & \\
\hline & & 1000 & 42.07 & \\
\hline & & 1001 & 42.03 & \\
\hline & & 1010 & 42.04 & \\
\hline & & 1011 & 42.00 & \\
\hline & & 1100 & 42.04 & \\
\hline & & 1101 & 42.03 & \\
\hline & & 1110 & 42.01 & \\
\hline & & 1111 & 41.97 & Min PAPR \\
\hline
\end{tabular}


Table 15: Category D - PAPR for Technical Parameters;

4 Augmented Bits, 256 QAM \& 32,000 subcarriers Balance Sequence for 41220 bits

\begin{tabular}{|c|c|c|c|c|}
\hline $\begin{array}{c}\text { Constellation } \\
\text { Mode }\end{array}$ & $\begin{array}{c}\text { No. of } \\
\text { Scrambling } \\
\text { Bits }\end{array}$ & $\begin{array}{l}\text { Scrambling } \\
\text { Sequence }\end{array}$ & PAPR & Comment \\
\hline \multirow[t]{16}{*}{256 QAM } & 4 & 0000 & 36.79 & \\
\hline & & 0001 & 36.55 & Min PAPR \\
\hline & & 0010 & 36.87 & \\
\hline & & 0011 & 36.84 & \\
\hline & & 0100 & 36.76 & \\
\hline & & 0101 & 36.72 & \\
\hline & & 0110 & 36.84 & \\
\hline & & 0111 & 36.84 & \\
\hline & & 1000 & 36.87 & \\
\hline & & 1001 & 36.84 & \\
\hline & & 1010 & 36.96 & Max PAPR \\
\hline & & 1011 & 36.93 & \\
\hline & & 1100 & 36.84 & \\
\hline & & 1101 & 36.81 & \\
\hline & & 1110 & 36.93 & \\
\hline & & 1111 & 36.90 & \\
\hline
\end{tabular}

\subsection{SUMMARY}

The performance results for each category of technical specification are summarised below:

\section{A. CATEGORY A - PAPR PERFORMANCE: 256 OAM: 32,000 SUBCARRIERS}

The results are only favourable, if 2 additional bits are used, taking into the fact that without any reduction technique the PAPR is $12.27 \mathrm{~dB}$. The use of 1,3 , or 4 bits causes performance to worsen.

\section{B. CATEGORY B- PAPR PERFORMANCE; 64 QAM; 32,000 SUBCARRIERS}

The results are indifferent to the addition of 1 bit is used, taking into the fact that without any reduction technique the PAPR is $11.84 \mathrm{~dB}$. The use of 2,3 , or 4 bits causes performance to worsen.

\section{CATEGORY C- PAPR PERFORMANCE 256 QAM; 8,000 SUBCARRIERS}

The results are only favourable, if either 2 or 3 additional bits are used, taking into the fact that without any reduction technique the PAPR is $10.5 \mathrm{~dB}$. The use of 1 or 4 bits causes performance to worsen.

\section{CATEGORY D- PAPR PERFORMANCE 256 QAM;} 32,000 SUBCARRIERS; BALANCED ONES \& ZEROES

An all ONES or ZEROES bits sequence for the total $41220+4=$ 41224 bits does lead to a tremendous increase of PAPR of 41 $\mathrm{dB}$. This is a result of high correlation among the sub-carriers summing to a high peak value. The balanced sequence leads to PAPR of about $37 \mathrm{~dB}$. Although there is slight reduction in PAPR, the result indicates that there is too much correlation among the sub-carriers. Such an increase would damage the High Power Amplifier and must be avoided.

\subsection{DISCUSSION}

Guided Scrambling does introduce redundancy, and hence the number of augmented bits have to be kept to a minimum. From the results, 1, 3 or 4 additional bits does not lead to any improvement but instead worsen the PAPR. The exception is DVB-T2 configuration mode of 64 QAM and 32,000 subcarriers. Only 2 extra bits are necessary which can be considered a tradeoff between improving PAPR and lowering the redundancy. The DVB-T2 configuration has to be specified and compared with the situation when there is no PAPR minimisation technique. This procedure provides a clearer picture and an effective comparison. Category B (2 Augmented Bits, 256 QAM \& 32,000 subcarriers) shows that without any PAPR is $12.27 \mathrm{~dB}$. In the case when Guided Scrambling is applied, the PAPR value is $11.84 \mathrm{~dB}$. The actual result is that, only $0.43 \mathrm{~dB}$ is achieved suggesting that improvements need to be made to the design.

\subsection{CONCLUSION AND FUTURE WORK}

This research study has shown that Guided Scrambling can indeed be used for the reduction of PAPR. Future work would investigate Tone Reservation technique that allocates certain subcarriers to generate additional information that minimizes the PAPR. The finalised project would incorporate both designs such that the PAPR is reduced significantly. High Peak to Average Power Ratio is a serious impairment of OFDM based Digital Radio and TV Broadcast system. Hence, many researchers are working on designs that can reduce PAPR. Finally, it has already been officially announced that Malaysia would be starting Digital Terrestrial TV Broadcasting by 2018. The decision is in line with international efforts to migrate from analogue to digital broadcasting. Many countries have already implemented Digital Switch Over (DSO) with the result that free to air Digital HDTV programmes are available to the public by terrestrial transmission. Hence, research in this area would be beneficial to both the local and international broadcast industry. The main objectives are mitigating transistor component failure in the High Power Amplifier stage and increasing energy efficiency of digital transmitters.

\subsection{ACKNOWLEDGEMENT}

The author wishes to acknowledge the Research Department, British Broadcasting Corporation (BBC), United Kingdom and in particular Oliver Haffenden for allowing the DVB-T2 Common Simulation Platform to be freely available to researchers in the field of Digital Terrestrial TV Broadcasting.

\section{REFERENCES}

[1] W. Fischer. Digital Video and Audio Broadcasting Technology, A Practical Engineering Guide, (2010) Third Edition, Springer. ISBN 978-3-642-11611-7.

[2] Yasser Rahmatallah, Seshadri Mohan (2013). "Peak To Average Power Ratio Reduction in OFDM Systems: A Survey and Taxonomy." IEEE Communications Surveys \& Tutorials, Vol 15, No 4, Fourth Quarter.

[3] I.J. Fair, W.D. Grover, W.A. Krzymien and R.I. MacDonald (1991)."Guided scrambling: a new line coding technique for high bit rate fiber optic transmission systems." IEEE Trans. Communications, vol. 39, pp. 289-297. 


\section{GUIDED SCRAMBLING AS A PEAK TO AVERAGE POWER RATIO REDUCTION \\ TECHNIQUE FOR DIGITAL VIDEO BROADCASTING - TERRESRIAL 2}

[4] Y. Xin and I J. Fair (2003). "Peak-to-average power ratio reduction of an OFDM signal using guided scrambling coding." IEEE Global Telecommunication Conf. (GLOBECOM),San Francisco, CA, vol. 4, 2003, pp. 2390-2394.

[5] C.L. Wang, Y.Q. Yang and F.H. Huang (2007). "A LowComplexity Peak-to-Average Power Ratio Reduction Technique for OFDM Systems Using Guided Scrambling Coding." IEEE 65th Vehicular Technology Conference VTC.

[6] I.J. Fair (1995). "Characterisation of Guided Scrambling." Ph.D Thesis, University of Victoria, Canada.

[7] I. J. Fair, D L. Martin (2015) "Generation of balanced quadrature phase shift keyed sequences through guided scrambling." IET Communications vol. 9, iss: 11 pp: 1404-1411.
[8] T. Park and J. Lee (2014) "Worst Case Performance Assessment of DC-Free Guided Scrambling Coding by Integer Programming Model.” IEEE Trans. Magnetics, vol. 50, no. 7.

[9] O. Haffenden (2011) "DVB-T2 Common Simulation Platform" BBC Research White Paper WHP 196.

[10] Digital Video Broadcasting (DVB); Frame structure channel coding and modulation for a second generation digital terrestrial television broadcasting system (DVB-T2) (2012), European Standard ETSI EN 302755 V1.3.1.

[11] Fuqin Xiong, (2006). Digital Modulation Techniques, Artech House, Second Edition. ISBN 1-58053-863-0.

\section{PROFILES}

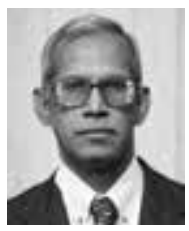

IR. V. JEEWA is presently attached to the Lee Kong Chian Faculty of Engineering and Science, Universiti Tunku Abdul Rahman, Malaysia as part of the academic staff holding the post of Specialist II. He is also conducting research into Digital Broadcasting and pursuing the Ph.D in the same field. 